Research article

\title{
Efficient protocol of complete inventory for tree regeneration and recruitment studies over one hectare in selected tropical natural forests, Kenya
}

\author{
Joseph Hitimana ${ }^{1,2}$, James Legilisho Ole Kiyiapi ${ }^{1}$ and Balozi Kirongo Bekuta ${ }^{1}$ \\ ${ }^{1}$ University of Eldoret; P.O.Box. 1125 Eldoret 30100 \\ ${ }^{2}$ University of Kabianga, Kenya
}

*Corresponding Author: hitimanajh@yahoo.com

[Accepted: 30 October 2019]

\begin{abstract}
This study sought to establish an efficient inventory protocol to estimate regeneration stock and dynamics in natural forests. Field and computer outputs were integrated to develop complete inventory protocol for selected natural forest types in Kenya. Inventory cost and precision for four plot sizes $(5 \mathrm{~m} \times 5 \mathrm{~m}, 10 \mathrm{~m} \times 5 \mathrm{~m}, 10 \mathrm{~m} \times 10 \mathrm{~m}$ and $20 \mathrm{~m} \times 20 \mathrm{~m})$ were determined and compared. Specific objectives were to determine (i) precision levels of estimating tree seedling density using different plot sizes across forest types; and (ii) optimum plot size which minimise both sampling error and inventory effort for use in each forest type. Seedling counts and time taken per plot were recorded systematically over 400, 200, 100 and 25 plots ha $^{-1}$ for the respective plot sizes. Larger plots and their data were created by merging smaller ones through programming with $\mathrm{R}$ Software. Smallest population mean-variance, $\sigma^{2} N^{-1}$ was obtained using data from $5 \mathrm{~m} \times 5 \mathrm{~m}$ plots. Both precision and inventory effort varied with plot size used, but in reverse directions. Seedlings population mean errors were $15.4 \%$ of the mean for rain forest, $14.7 \%$ for moist montane forest and $9.9 \%$ for dry forest type. Inventory cost decreased with increasing data compilation unit size, e.g., $50.42 \mathrm{hrs} \mathrm{ha}^{-1}$ for $25 \mathrm{~m}^{2}$ unit to $3.21 \mathrm{hrs} \mathrm{ha}^{-1}$ for $400 \mathrm{~m}^{2}$ unit in rainforest. Similar trend was observed in other forest types. Recommended plot sizes for tree seedlings are $75 \mathrm{~m}^{2} ; 62.4 \mathrm{~m}^{2}$ and $88.4 \mathrm{~m}^{2}$ for Kakamega rain forest, Mt Elgon montane forest and Loruk dry woodland forest, respectively. These plot sizes gave acceptable uncertainty levels between $\pm 11 \%$ and $\pm 17 \%$ of mean estimate $\mathrm{ha}^{-1}$. Tree diameter distributions from $5 \mathrm{~m} \times 5 \mathrm{~m}$ plots revealed that tree component recruitment was irregular over time across forest types.
\end{abstract}

Keywords: Climatic factors - Deciduous - Homegarden - Meitei - Phenology.

[Cite as: Hitimana J, Kiyiapi JLO \& Bekuta BK (2019) Efficient protocol of complete inventory for tree regeneration and recruitment studies over one hectare in selected tropical natural forests, Kenya. Tropical Plant Research 6(3): 376-392]

\section{INTRODUCTION}

According to Weiskittel et al. (2011), regeneration is the renewal of a forest by natural self-sown seed, coppice, suckers, lignotubers, or by artificial means. Recruitment refers to individuals that reach a prescribed size or established seedlings that have survived its first year, following germination. Both regeneration and recruitment processes significantly influence the outcome of forest growth-model projections; particularly in areas dominated by naturally regenerated forests (Weiskittel et al. 2011). The number of tree seedlings is used as a measure of regeneration potential of a forest; and may be assessed in sample plots, subplots or microplots (McWilliams et al. 2015). Rates of recruitment are often gaged from analyses of tree diameter size distribution curves which reflect tree regeneration, growth and mortality in the forest over time (Churski 2006, Wang et al. 2009). For example, the logarithm of the number of trees over diameter class becomes a straight line for regular recruitment and sufficient regeneration (Devis \& Johnson 1987). Fluctuating trend line indicates good but discontinuous regeneration over time which results in a wave-like recruitment of small individuals into the larger size classes (Harper 1977, Devis \& Johnson 1987, Poorter et al. 1996, Hitimana et al. 2004).

Forest regeneration and recruitment are attributes of high ecological, silvicultural and conservation 
significance in forest conservation and management (Serna 1986, Grainger 1993, Schreuder et al. 1993, Wong et al. 2001, Bellefontaine et al. 2002, Sarkar \& Devi 2014, Pandey et al. 2016, Raj 2018). Information on regeneration in forests is needed for making policy decisions and for strategic planning of rehabilitation and/or restoration of degraded ecosystems (Evans \& Turnbull 2004); or to conserve threatened species and other components of biodiversity that are valuable to mankind (Groombridge \& Jenkins 2000, Njunge \& Mugo 2011, Oldfield \& Newton 2012, Hanief et al. 2016). Tropical natural forests and woodlands are of diverse entities with lesser-known and understood species mix and stand structure (Girma 2012, Mulatu et al. 2017). These ecosystems are difficult to analyse and understand in their pristine state (Grainger 1993, Singh 1993, Lanly 1997) due to lack of established; reliable and widely acceptable inventory protocols (Arellano et al. 2016). Inventory protocol components consist of plot size, plot shape, number of plots and spatial or temporal pattern of the same units (Wong et al. 2001).

An efficient inventory protocol must be accurate, precise and cost-effective (Husch et al. 2003). According to Wong et al. (2001), deciding on how many plots to be used in an inventory is critically required for the management of sampling errors. The greater the number of plots, the smaller the sampling error; and the more precise and potentially accurate the results will be. However, the relationship between the number of plots and sampling error is non-linear, with diminishing returns as numbers increase (Shiver \& Borders 1996, Nassiuma 2000). There is need to determine an optimal sample size below or above which the precision or accuracy levels may fall to undesirable level. The choice between "few but large" and "many but small" plot sizes has implications on both the cost and precision in opposite directions. The acceptable target sampling error in documented forest inventories is between 10 and $20 \%$ of the mean (Wong et al. 2001) but not known for tropical natural forests in Kenya.

The cost of enumerating items in a plot is also critical but not well documented. The relationship between plot size and cost or effort of inventory would enable to identify and use cost-effective inventory protocols. In this study, a sampling scheme for tree seedling inventory refers to a combination of sampling design, plot size and sampling intensity used to assess seedlings (individuals $<1 \mathrm{~cm}$ DBH and not taller than $150 \mathrm{~cm}$ ) over one hectare. There is little information on the relative efficiency of different schemes to floristic assessment in tropical natural forests (Herold \& Skutsch 2011, Shijo et al. 2013, Nduati et al. 2016). There is need for research on accurate and efficient forest inventory schemes to be used in resource assessment for the support of sustainable forest management and conservation of the diverse tropical forests and woodland formations, which are highly variable in composition, diversity, physical and dynamic structures (Hemp 2006, Talbot et al. 2014).

There is a gap for research towards standardisation of inventory designs to enhance monitoring of forest resource conditions within and across habitats (Feld et al. 2009, Hicks et al. 2014). We note, however, that field methods are situation-specific (Schreuder et al. 1993, Burkhart \& Tome 2012, Arellano et al. 2016); and that they target specific population characteristics (Gillison \& Brower 1985, Philip 1994, Myers \& Patil 1995, Greenwood 1996, Wong et al. 2001). Therefore, field protocols should be calibrated and validated for suitability before they are adopted (Pretzsch 2009, Weiskittel et al. 2011). In validating inventory methods, target species and ecosystem components should be identified and evaluated using cost-effective studies.

Forest resource managers, including silviculturists, lack accurate and timely quantitative resource information on regeneration and other parameters to make good decisions (Schreuder et al. 1993, Wong et al. 2001). It is worth noting that tropical flora remains chronically understudied and that the lack of floristic understanding hampers ecological research and large-scale conservation plans (Phillips et al. 2003). Precision level, accuracy and cost are major concepts in selecting efficient sampling schemes (Jayaraman 1999, Wong et al. 2001). The precision is high when errors are small; and accuracy is high when the estimated value is close to the population true value (Nassiuma 2000, Wong et al. 2001). The lack of knowledge of the true value of a variable is also known as uncertainty which is measured by the sampling error of an inventory (Lackmann 2011). According to Morais \& Schreuber (1997), sampling inventories should provide the statistical precision of estimated quantities within accepted limit, that is, uncertainty levels of estimates must be disclosed. In many cases, inventories are designed to achieve a specific precision level expressed by a fixed sampling error.

This study sought to develop field sampling protocol suitable for use to count and quantify regeneration in selected tropical natural forests, using a " 1 ha-method" (Alder \& Synnott 1992, Wong et al. 2001, Phillips et al. 2003) by determining optimum data compilation unit size within the one-hectare standard area. The main objective was to provide efficient protocol to use in forest tree seedling stock inventories across the 'tropical rain forest- moist montane forest dryland forests /woodlands gradient. Specific objectives were: (i) to quantify population mean-variance of the seedling stocks across selected tropical rainforest- moist montane forest - dry 
woodland forest spectrum in Kenya; (ii) to determine efficient and cost-effective data compilation unit size to estimate the number of seedlings over one hectare and a high precision level for each natural forest type; and (iii) determine recruitment trends of the tree component in the studied forest types. It was hypothesized that: (i) Precision levels of forest regeneration estimates from complete inventory per hectare vary with used plot size in mixed natural forests; (ii) there exist optimum plot size [i.e. data compilation unit size] in a complete inventory of tree seedlings in the selected forest types; (iii) regeneration dynamics is regular over time leading to stable recruitment process of the tree component in the selected forest types.

\section{MATERIALS AND METHODS}

Study area and sites

Data used to test the performance of different plot sizes were collected from three distinct forest sites that mimic a climate gradient from low rainfall dry zone (Loruk woodland; $<700 \mathrm{~mm}$ year ${ }^{-1}$ ) to high rainfall humid zone (Kakamega rainforest; 1900-2000 mm year ${ }^{-1}$ ) through the intermediate moist zone (Mt Elgon forest; 1400-1700 mm year ${ }^{-1}$ ) (Kokwaro 1988, Fashing et al. 2003, Hitimana et al. 2004, Mutiso et al. 2013). These sites also differed in altitude from $<1000 \mathrm{~m}$ a.s.l. at Loruk (low altitude dry woodland) to $>2000 \mathrm{~m}$ at Mt. Elgon (montane forest) through $<1600 \mathrm{~m}$ a.s.l. at Kakamega (mid-elevation tropical rain forest). In terms of ownership and governance; Loruk woodland is community-owned and under silvopastoral land use system. Kakamega and Mt Elgon are protected state-owned forests; surrounded by highly populated settlements involved in mixed farming. Therefore; selected forest types and sites represent ecological; climatic and socio-economic complexities of natural forest resources in Kenya and the tropics. Kakamega mixed tropical rainforest (TRF); Mt Elgon moist lower montane forest (MMF) and Loruk dry woodland forest (DWF) locations in Kenya are shown in figure 1.

The Kakamega forest vegetation is influenced by high rainfall and average annual temperature of $20^{\circ} \mathrm{C}$ with February as the hottest month $\left(21^{\circ} \mathrm{C}\right)$ and July as the coldest month $\left(19^{\circ} \mathrm{C}\right)$. Despite past disturbances, the forest is on the recovery path and near climax development stage (Mutiso et al. 2013). Mt. Elgon forest ecosystem (located on the steep slopes of the extinct volcano and occurring at a height of $4321 \mathrm{~m}$ a.s.l. on the Kenya Uganda boarder) is also influenced by high rainfall and mean annual temperature of $15-18^{\circ} \mathrm{C}$ (Jaetzold \& Schmidt 1983, Hitimana 2000, Hitimana et al. 2004). It is in a building phase of succession, following intensive historic selective logging activities (Hitimana et al. 2004) which affected the population structure and regeneration of some target species (Hitimana et al. 2010). Finally, Loruk woodland forest is a typical dryland ecosystem with short trees ( $<6 \mathrm{~m}$ on average; Hitimana et al. 2019) and poorly developed undergrowth, in the wider Baringo landscape of Kenya (Kiyiapi 1994, Omondi 2016). The climate is characterized by erratic rainfall and high temperatures $\left(22-25^{\circ} \mathrm{C}\right)$.

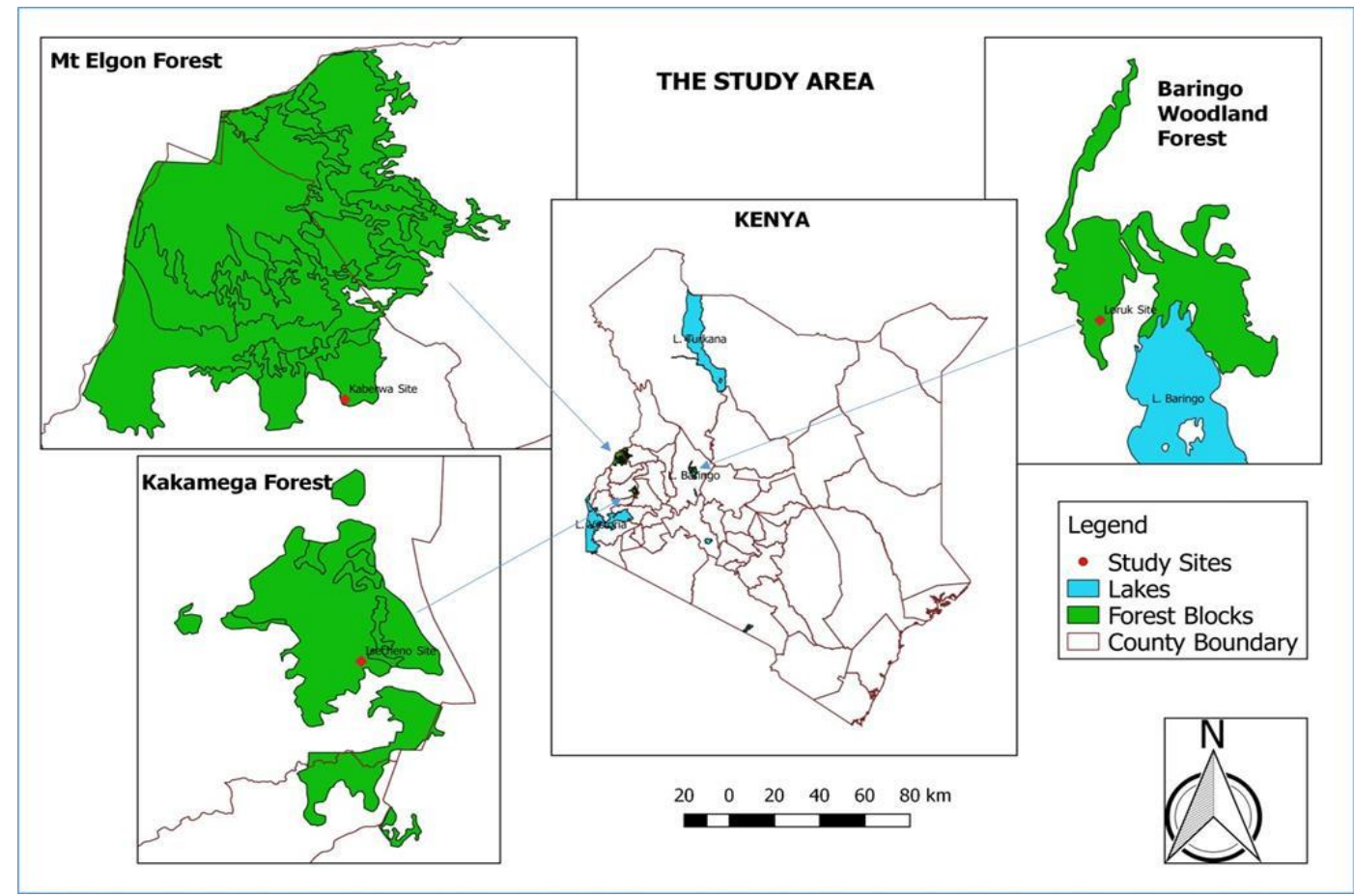

Figure 1. Location of study sites in kenya. 


\section{Field methods and simulations}

Fieldwork and data organization: Data collection over 1 ha-forest unit of reference was done in the field to determine "true" values of forest attributes for each forest type. It was achieved by establishing four hundred $5 \mathrm{~m} \times 5 \mathrm{~m}$ plots (Fig. 2) to ensure accurate field observations of forest attributes including seedlings. A complete enumeration of seedlings was systematically done within $1 \mathrm{~m}^{2}$ (i.e. $1 \mathrm{~m} \times 1 \mathrm{~m}$ ) subplots, one after the other, within the $5 \mathrm{~m} \times 5 \mathrm{~m}$ plots in order to enhance accuracy of observations on seedlings. Records on seedlings from were put together for each $5 \mathrm{~m} \times 5 \mathrm{~m}$ smallest data compilation unit. Data were recorded on field sheets and were later transferred into the computer MS Excel spreadsheet. Each $5 \mathrm{~m} \times 5 \mathrm{~m}$ unit was assigned a unique code (Fig. 2 for illustration) for easy identification, retrieval and manipulation during data analysis. Data were organized per forest type and plot size.

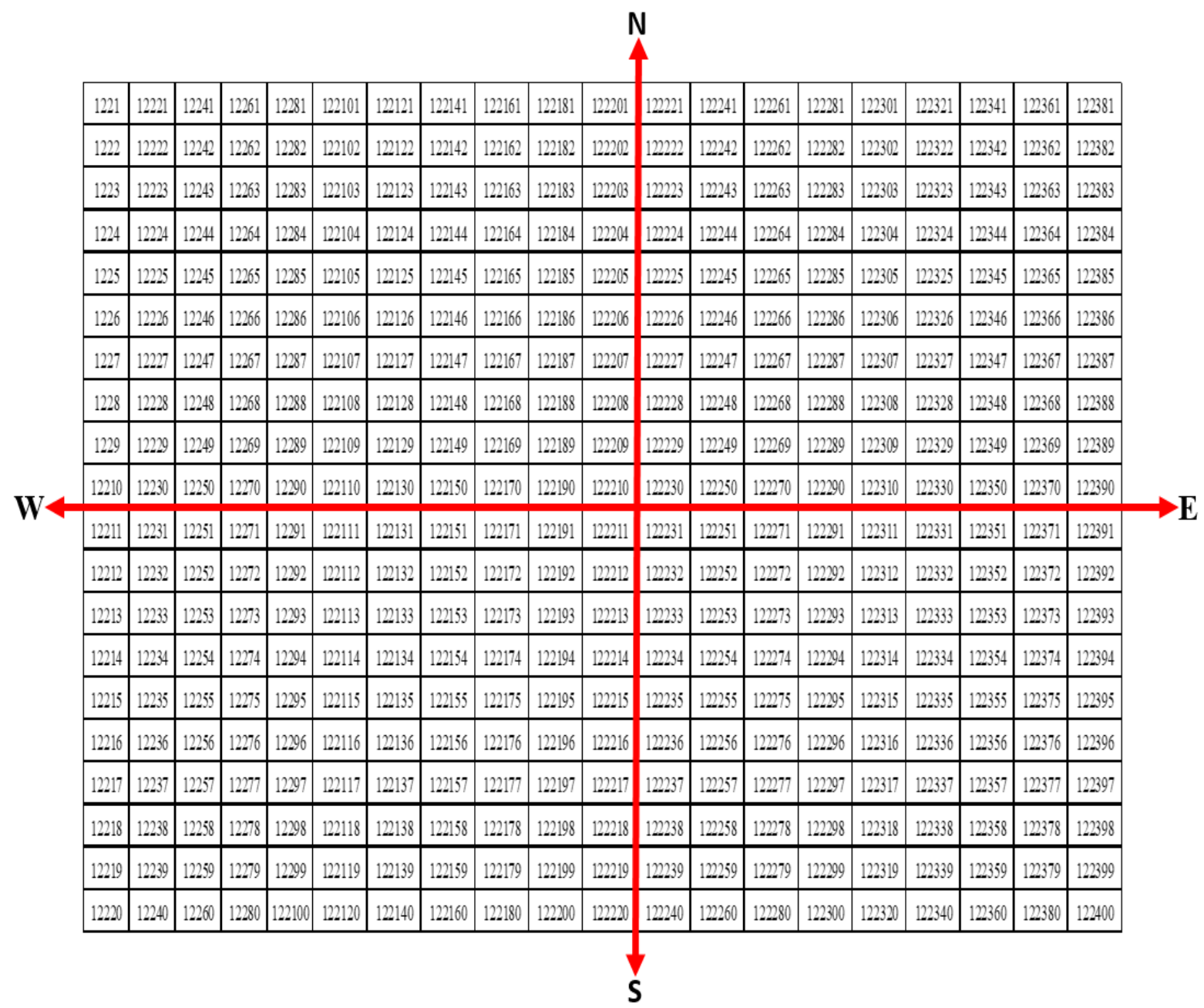

Figure 2. Example of field arrangement for four hundred $5 \mathrm{~m}$ by $5 \mathrm{~m}$ plots in the forest. [Each cell with a number represent a coded $5 \mathrm{~m} \mathrm{x} 5 \mathrm{~m}$ plot for easy data set identification; entry; storage; retrieval and use in sampling simulation activity. First three digits denote the forest site (122-Kakamega site; 111- Mt Elgon site; 131- Loruk site). The subsequent digits represent serial plot number within the $100 \mathrm{~m} \times 100 \mathrm{~m}$ frame (Hitimana et al. 2019)]

Study variables: Study variables include plot size, sampling intensity, inventory cost per hectare, percentage sampling error and number of trees in different diameter size classes.

Plot size: Four plot sizes were tested for efficiency and cost-effectiveness as data compilation units (Table 1) for seedling stocks over one hectare $(100 \mathrm{~m} \times 100 \mathrm{~m})$. Plot sizes larger than $5 \mathrm{~m} \times 5 \mathrm{~m}$ were formed by merging contiguous smaller units through the confounding technique in R software: $5 \mathrm{~m} \times 5 \mathrm{~m} \rightarrow 10 \mathrm{~m} \times 5 \mathrm{~m} \rightarrow 10$ $\mathrm{m} \times 10 \mathrm{~m} \rightarrow 20 \mathrm{~m} \times 20 \mathrm{~m}$ (see R codes in Appendix I). Display of plots of different sizes over 1 ha area is in Appendix II.A-D. The merging of smaller units was automatically associated with collating records they contained. Totals, averages and other data computations in each unit were performed in R Software.

Sampling intensity: Complete inventory (100\% intensity) of seedlings over 1 ha (100 $\mathrm{m} \times 100 \mathrm{~m}$ forest unit) was carried out using the four different plot sizes in each selected forest type. The number of compilation units for each plot size used varied from 25 to 400 (Table 1). 
Table 1. Number of plots $(\mathrm{N})$ in a hectare for different plot sizes.

\begin{tabular}{|c|c|c|c|c|}
\hline \multirow[b]{2}{*}{$\begin{array}{l}\text { Sampling Intensity } \\
(\%)^{1}\end{array}$} & \multicolumn{4}{|c|}{ Plot Sizes } \\
\hline & $\begin{array}{r}5 \mathrm{~m} \times 5 \mathrm{~m} \\
\left(25 \mathrm{~m}^{2}\right)\end{array}$ & $\begin{array}{r}10 \mathrm{~m} \times 5 \mathrm{~m} \\
\left(50 \mathrm{~m}^{2}\right)\end{array}$ & $\begin{array}{r}10 \mathrm{~m} \times 10 \mathrm{~m} \\
\left(100 \mathrm{~m}^{2}\right)\end{array}$ & $\begin{array}{r}20 \mathrm{~m} \times 20 \mathrm{~m} \\
\left(400 \mathrm{~m}^{2}\right)\end{array}$ \\
\hline 100 & 400 & 200 & 100 & 25 \\
\hline
\end{tabular}

Note: ${ }^{1} \mathrm{n}=$ Sample size (no. of sample plots selected from one- hectare forest unit); $\mathrm{N}=$ population size (total number of plots in a one- hectare forest)

Inventory cost over one hectare: The inventory cost or effort per hectare was determined for each plot size 25 $\mathrm{m}^{2}, 50 \mathrm{~m}^{2}, 100 \mathrm{~m}^{2}$ and $400 \mathrm{~m}^{2}$. Sampling effort was measured by the time taken to complete work within the 1 ha plot area. Time taken to collect data in each $5 \mathrm{~m} \times 5 \mathrm{~m}$ plot was recorded in the field using a watch chronometer. The forest inventory protocol developed for one hectare is a standard to be used in any inventory where a network of several 1 ha plots may be established as permanent sample plots or independent temporal sampling plots (Picard et al. 2010, Brown \& Williams 2016).

Percentage sampling error: Conventionally, the precision of an estimate is measured by the sampling error \% (uncertainty level \%) (Lackmann 2011, Klauberg et al. 2016) (Equation 1). Sampling error was computed for each plot size for different sampling intensities, up to the complete inventory, and based on standard error of the mean (Equation 2).

$$
\text { Sampling Error } \%=\frac{1 / 2(95 \% \text { Confidence interval width })}{\mu} \times 100=\frac{S E \times t}{\mu} \times 100 \ldots \ldots \ldots . . \text { (Equation 1) }
$$

where, $\mu$ is the mean of the distribution; and sampling error (error \%) is the 95 percent confidence interval expressed as a percentage of the mean.

Standard error of the mean (SE) for each plot size was computed as follows (Equation 2):

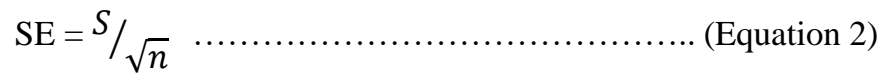

where, $\mathrm{S}=$ Standard deviation given per hectare for each plot size; $\mathrm{n}=$ sample size (i.e. no. of plots for $100 \%$ intensity and plot size used).

Number of tree seedlings, saplings and large trees: Individuals in each tree development stage (seedling, sapling and large trees) were counted from each $5 \mathrm{~m} \times 5 \mathrm{~m}$ plot. Diameter at breast height (DBH), measured at $1.3 \mathrm{~m}$ from ground level, was used to distinguish saplings from individuals in other development stages. Veneer caliper was used to measure small size trees e.g. saplings; and large calipers were used on larger diameter trees (Avery \& Burkhart 2015). In this study, seedlings were individuals $<1 \mathrm{~cm} \mathrm{DBH}$ and $<1.50 \mathrm{~m}$ tall; saplings were small trees with $1-5 \mathrm{~cm} \mathrm{DBH}$; and large trees were individuals $\geq 5 \mathrm{~cm}$ DBH (adopted from Stride et al. 2018). Tree diameter size distributions are often used to indicate rates of recruitment, growth and mortality in a forest over time, and they are used to analyse forest stability, regeneration history and impact of past disturbances (Poore \& Sayer 1991). The numbers of individuals were converted per hectare for each DBH size class.

\section{Data analysis}

Efficient plot sizes for natural tree seedlings stock inventories in "1 ha-method": Population mean-variance for seedling stocks in each selected forest type was determined based on $5 \mathrm{~m} \times 5 \mathrm{~m}$ plot size and $100 \%$ intensity (complete inventory) using (Equation 3) and interpreted (Hitimana et al. 2019).

$$
\text { Population mean variance }=\frac{\sigma^{2}}{N}
$$

where, $\sigma^{2}=$ population variance; $\mathrm{N}=$ Total number of plots per ha which varied with plot size.

This mean variance was used as a measure of standard [inherent] variability for the density of seedlings in the forest. It was also used to compute standard [inherent] sampling error percent. Percentage sampling error was computed for each plot size (compilation unit type) for seedling counts.

Both sampling error \% and inventory effort (cost) were plotted on the same graph as dependent variables over plot size (independent variable). The lower the sampling error $\%$ produced by a plot size, the more precise, reliable and suitable is that size as a compilation unit. The optimum plot size was identified at the intersection of the two-line graphs (i.e. inventory cost and sampling error \% line graphs). Regression analysis (IBM SPSS) was applied to obtain regression equations and ascertain the probability level of significance of the observed regression relationships. Solving both equations simultaneously enabled the identification of optimum plot size for each forest type. 
Regeneration variability and recruitment characteristics in studied forests: Recruitment of tree individuals from one development stage to the other was evaluated based on the ratios of number of seedlings - to - number of saplings; and the ratios of individuals in different successive diameter size classes (the "q" ratio; Equation 4) as dependent variables and diameter classes as independent variable. The graph of q over DBH classes is a measure of how regular regeneration and recruitment have been in the forest (Hitimana et al. 2004, Marimon et al. 2012).

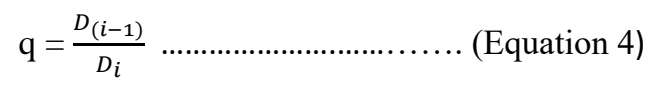

where, $\mathrm{D}_{(\mathrm{i}-1)}$ is density in a lower DBH class; and $\mathrm{D}_{\mathrm{i}}$ is density in the immediate upper DBH class.

\section{RESULTS AND DISCUSSION}

Efficient plot sizes for natural tree seedling stock inventories in "1 ha-method"

Inherent true variability of seedling stocking in the selected forests determined based on $5 \mathrm{~m} \times 5 \mathrm{~m}$ plot size and complete inventory is as shown in table 2.

Table 2. Inherent true variability of tree seedlings stocking per hectare compiled using $5 \mathrm{~m} \times 5 \mathrm{~m}$ plot size for three natural forest types in Kenya.

\begin{tabular}{llrrr}
\hline Forest attribute & Forest & \multicolumn{1}{c}{ Smallest $\boldsymbol{\sigma}^{\mathbf{2}} / \boldsymbol{N}$} & Inventory cost $\left(\mathbf{h a} \mathbf{~ h}^{-\mathbf{1}}\right)$ & Plot size $(\mathbf{m} \times \mathbf{m})$ \\
\hline Seedlings ha & & & & \\
& TRF & $1,726,559.16$ & 0.02 & $5 \times 5$ \\
& MMF & $223,003.91$ & 0.02 & $5 \times 5$ \\
& DWF & $3,033.49$ & 0.04 & $5 \times 5$ \\
\hline
\end{tabular}

Observed true variability in the distribution of number of seedlings in the forest varied from one plot size to the other; and was inversely proportional to the sample size. Inherent variability in tree seedling stocks was by far highest in tropical rain forest; intermediate in tropical moist montane forest and lowest in dry woodland forest. This variability in tropical rainforest (TRF) was 7.74 and 569 times that of Mt Elgon tropical moist montane forest (MMF) and Loruk dry woodland forest (DWF); respectively. If the extent of variability indicates the level of complexity of the variable under consideration, then the complexity continuum in tree regeneration from the highest across forest types to the lowest levels was found to be TRF - MMF - DWF.

For $100 \%$ inventory over 1 ha, the choice of plot size influences the cost of operations, level of uncertainty and level of precision (Table 3). The smaller the sampling unit, the higher the cost of sampling was experienced. The choice between many small plots and a few larger plots for a constant sampling intensity makes a difference.

Table 3. Precision level and costs of complete tree seedlings inventory using different plot sizes per ha, for selected natural forests in Kenya.

\begin{tabular}{|c|c|c|c|c|c|c|c|c|c|c|c|c|}
\hline \multirow{2}{*}{$\begin{array}{l}\text { Plot } \\
\text { size } \\
\left(\mathbf{m}^{2}\right)\end{array}$} & \multicolumn{4}{|c|}{ Tropical rain forest } & \multicolumn{3}{|c|}{ Moist montane forest } & \multicolumn{5}{|c|}{ Dry woodland forest } \\
\hline & $\begin{array}{r}\text { Pop. } \\
\text { Mean }\end{array}$ & $\begin{array}{r}\text { Pop. } \\
\text { Error } \\
(\%)\end{array}$ & $\begin{array}{r}\text { Pop. } \\
\text { CV } \\
(\%)\end{array}$ & $\begin{array}{r}\text { Inventory } \\
\text { Cost } \\
\left(h^{\prime} \text { ha }^{-1}\right)\end{array}$ & $\begin{array}{r}\text { Pop. } \\
\text { Mean }\end{array}$ & $\begin{array}{r}\text { Pop. } \\
\text { Error } \\
(\%)\end{array}$ & $\begin{array}{r}\text { Pop. } \\
\text { CV } \\
(\%)\end{array}$ & $\begin{array}{r}\text { Inventory } \\
\text { Cost } \\
\left(\mathrm{hr} \mathrm{ha}^{-1}\right)\end{array}$ & $\begin{array}{l}\text { Pop. } \\
\text { Mean }\end{array}$ & $\begin{array}{r}\text { Pop. } \\
\text { Error } \\
(\%)\end{array}$ & $\begin{array}{r}\text { Pop. } \\
\text { CV } \\
(\%)\end{array}$ & $\begin{array}{r}\text { Inventory } \\
\text { Cost } \\
\left(\mathrm{hr} \mathrm{ha}^{-1}\right)\end{array}$ \\
\hline 25 & 16,764 & 15.4 & 157 & 50.42 & 6,279 & 14.7 & 150 & 40.68 & 1,094 & 9.9 & 101 & 22.38 \\
\hline 50 & 16,764 & 16.2 & 117 & 25.28 & 6,279 & 15.6 & 113 & 20.10 & 1,094 & 10.7 & 77 & 11.35 \\
\hline 100 & 16,764 & 18.2 & 92 & 12.70 & 6,279 & 18.0 & 91 & 9.98 & 1,094 & 11.9 & 61 & 5.65 \\
\hline 400 & 16,764 & 29.0 & 70 & 3.21 & 6,279 & 24.1 & 58 & 2.43 & 1,094 & 18.7 & 45 & 1.45 \\
\hline
\end{tabular}

Note: Plot size $\left(\mathrm{m}^{2}\right)=25 \rightarrow 5 \mathrm{~m} \times 5 \mathrm{~m} ; 50 \rightarrow 10 \mathrm{~m} \times 5 \mathrm{~m} ; 100 \rightarrow 10 \mathrm{~m} \times 10 \mathrm{~m} ; 400 \rightarrow 20 \mathrm{~m} \times 20 \mathrm{~m}$; Pop. Mean= Population Mean; Pop. Error $(\%)=$ Sampling error $(\%)=$ Uncertainty $(\%)=($ Standard Error* student's $t / m e a n) * 100$ as a measure of precision level; Pop. CV $(\%)=$ It measure levels of true inherent variability of seedlings stocking per hectare being reflected by a specific plot size.

The other aspect of efficient plot size is the desired precision level of the estimates. Sampling error is a measure of uncertainty level or bias which is inversely proportional to the precision level in a complete inventory context. The smaller the error, the higher is the precision level. In this study, the bias (error) decreased with decreasing plot size (Fig. 3). It means that, all factors held constant, smaller plot sizes were accurate and more precise. Smallest plot size $\left(25 \mathrm{~m}^{2}\right)$ produced highest internal variability $(\mathrm{CV} \%>100 \%)$ for all forest types (Table 3) and $400 \mathrm{~m}^{2}$ plots produced the lowest CV\%. Variability is an inherent property of the system of nature, and not of the analyst; thus, it can only be reduced by sampling entire populations or stratification of the area. Variability refers to the observed true heterogeneity or diversity of elements in a population and is an inherent property of the system of nature (Lackmann 2011). A trade-off between cost and precision levels determined the efficient plot sizes in different forests (Fig. 3). The precision of an inventory depends on the 
trade-off between using larger plots which have a lower inter-plot variance or using a larger number of smaller plots which tend to reduce the standard error of the mean (Evans \& Viengkham 2001). Plot sizes that balanced desired precision level (uncertainty \%) and cost were $75 \mathrm{~m}^{2}$ (CV between 92 and 117\%; Table 3) for TRF; 62.4 $\mathrm{m}^{2}$ (CV between 91 and 113\%) for M MF and $88.4 \mathrm{~m}^{2}$ (CV between 61 and 77\%) for DWF. These optimum compilation units (i.e. plots) result in $95 \%$ Confidence Interval of the total number of seedlings $\pm 17.0 \%$ of the total number of seedlings over one hectare within TRF $\pm 16.3 \%$ of the total number of seedlings over one hectare within MMF and $\pm 11.3 \%$ of the total number of seedlings over one hectare within DWF.
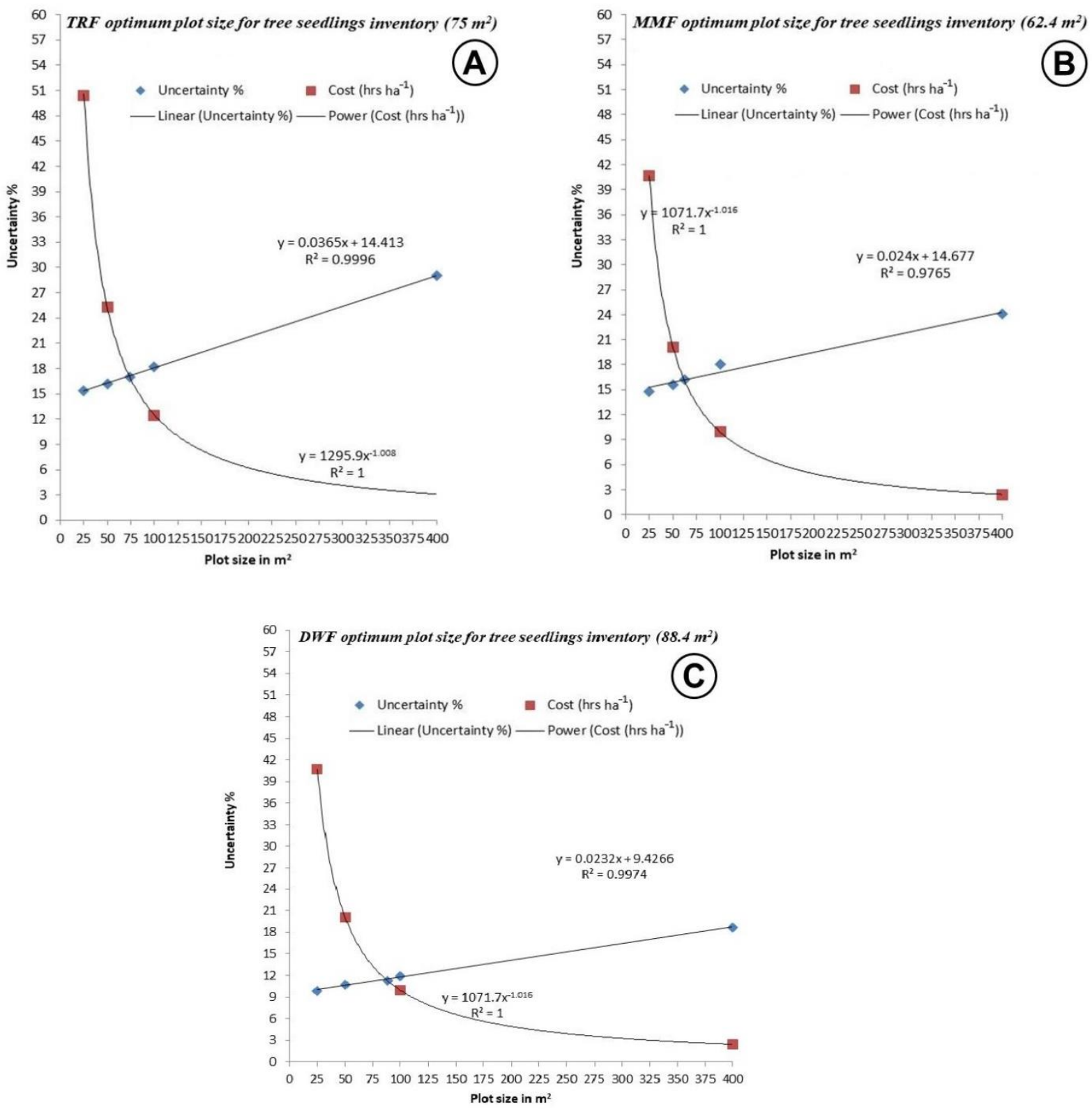

Figure 3. Efficient plot size for 100\% inventory of 1 hectare for the number of tree seedlings in Kenya: A, Kakamega tropical rain forest (TRF); B, Mt Elgon moist montane forest (MMF); C, Dry woodland forest (DWF).

The reliability levels of estimates in the three tropical natural forests in Kenya compare well with findings by Lackmann (2011) for estimation of carbon stock changes in complex forests [mean carbon stock $\pm 10 \%$ of the mean at $95 \%$ confidence and at a modest cost]; and with desired precision level by Cavalcanti et al. (2011) for plantation forests $( \pm 10 \%)$. The sampling errors associated with optimum plot sizes found in this study are also within the range of recommended precision levels for diagnostic inventories in Amazon forest (Klauberg et al. 2016), that is, $20 \%$ for two forest species assessment and $15 \%$ for one species assessment. Cielo-Filho et al. (2009) recommend $\pm 20 \%$ sampling error at $95 \%$ confidence level for tree species abundance and importance value estimates in a tropical forest stand in Brazil.

Data compilation units larger than $100 \mathrm{~m}^{2}$ (e.g. $10 \mathrm{~m} \times 10 \mathrm{~m}$ ) have low precision level (Table 3$)$ in the 1 hamethod. 
Regeneration variability and recruitment characteristics in studied forests

The proportion of tree seedlings ( $<1 \mathrm{~cm} \mathrm{DBH}$ individuals) dominated with $86 \%$ in the Kakamega tropical rainforest $\left(\mathrm{TRF}\right.$ ) (all sizes tree density $=19,448$ individuals $\mathrm{ha}^{-1}$ ) and $81 \%$ in Mt Elgon moist montane forest $(\mathrm{MMF})$ (total density $=7,711$ individuals $\mathrm{ha}^{-1}$ ). In Loruk dry woodland forest (DWF) (total density = 2,369 individuals $\mathrm{ha}^{-1}$ ); seedlings and saplings dominated almost equally with $46 \%$ and $41 \%$ relative abundances; respectively (Fig. 4). Saplings contributed only 8\% in both TRF and MMF; being under-represented if the reverse-J curve describing a stable natural forest is referred to (Devis \& Johnson 1987). These results indicate a deficient seedling stage in dry woodland forest and a deficient sapling stage in moist montane forest; where large trees were exceptionally more abundant than saplings. This shows a degenerating population if such trend in recruitment continues. In absolute terms, TRF had the highest stocking ha ${ }^{-1}$ (2.5 times than MMF and 8 times the stocking in DWF) in Kenya. Abiotic factors such as soil, topography, precipitation, temperature and drought are known to influence regeneration success including seeding; seed germination; tree seedling establishment and early sapling survival and growth (Schwartz \& Caro 2003, Principe et al. 2014).
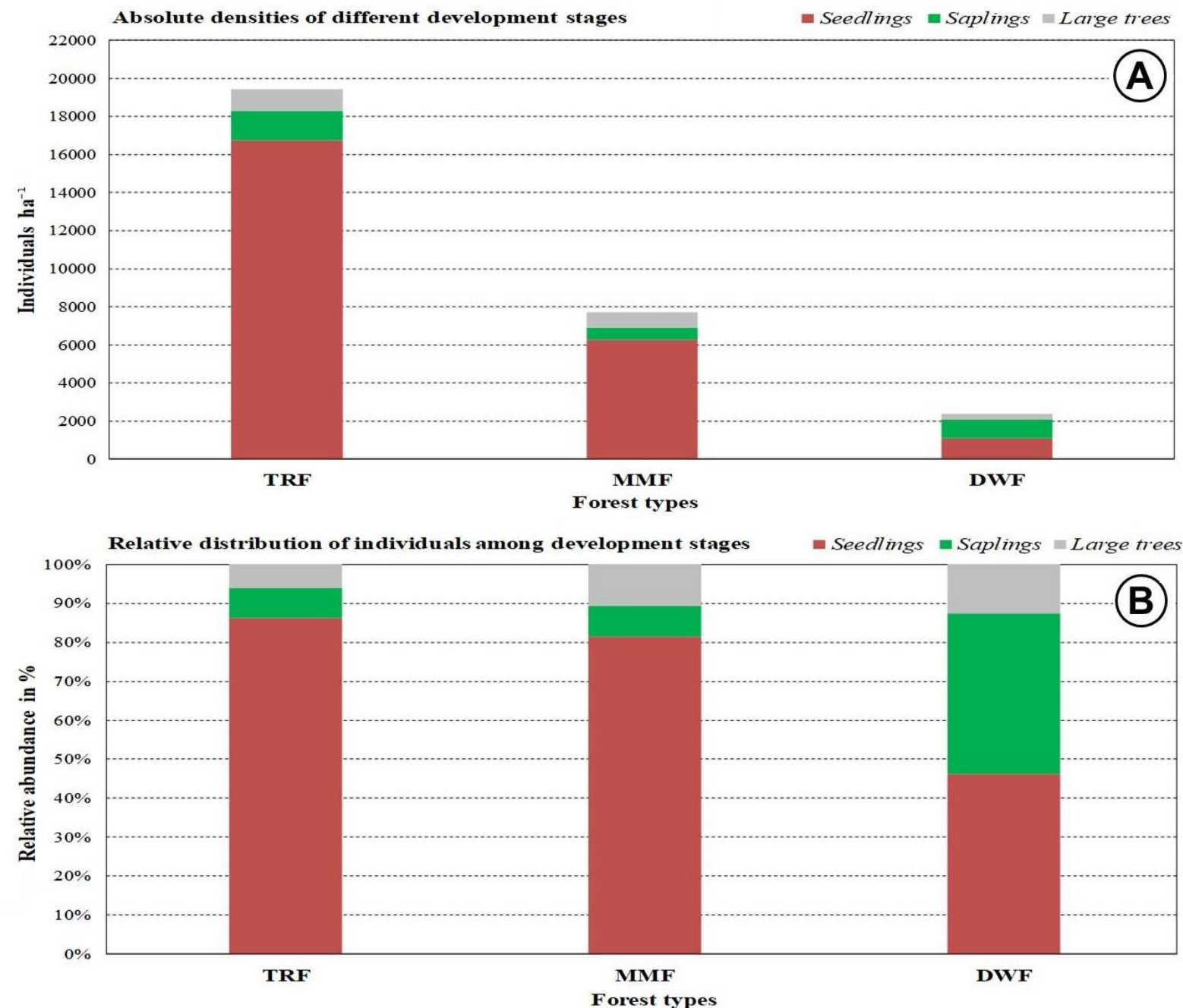

Figure 4. Recruitment patterns of trees for different tropical natural forest types in Kenya: A, Absolute density (Individuals $\left.\mathrm{ha}^{-1}\right)$; B, Relative distribution (Relative abundance in \%). [TRF $=$ Tropical rainforest; MMF= Moist montane forest; DWF= Dry Woodland Forest; Seedlings $=$ Individuals $<1 \mathrm{~cm}$ dbh and $<1.50 \mathrm{~m}$ tall; Saplings $=$ Small trees with $1-5 \mathrm{~cm}$ dbh; Large trees $=$ Individuals $>5 \mathrm{~cm} \mathrm{dbh]}$

Based on the q quotient (Fig. 5); regular recruitment was only observed in the tropical rainforest in tree sizes (post sapling size) up to about $110 \mathrm{~cm} \mathrm{DBH}$ class. Recruitment of trees in MMF Site followed same trend as in TRF Site up to $80 \mathrm{~cm}$ DBH class. However, at Mt Elgon Site; some exceptional events or processes occurred and distorted diameter size distribution for trees with $\mathrm{DBH}>50 \mathrm{~cm}$; causing drastic departure from the balanced trend observed in Kakamega tropical rain forest site. The narrower range of DBH classes in the DWF Site would suggest; notwithstanding environmental and ecological constraints to tree growth; that this ecosystem is the simplest and perhaps the youngest in succession. To this extent; tropical rain forest was judged more stable than the other forest types; and the woodland ecosystem was the least stable. Rising "q" quotient at the tail-end of 
diameter size distribution in TRF is characteristic of mature; self-regulating tropical forests. Protection and rehabilitation measures are needed in management and conservation of the structurally unstable ecosystems: MMF and DWF. Periodic monitoring programmes; say every 10 years; are encouraged to follow up the recovery and development processes over time.

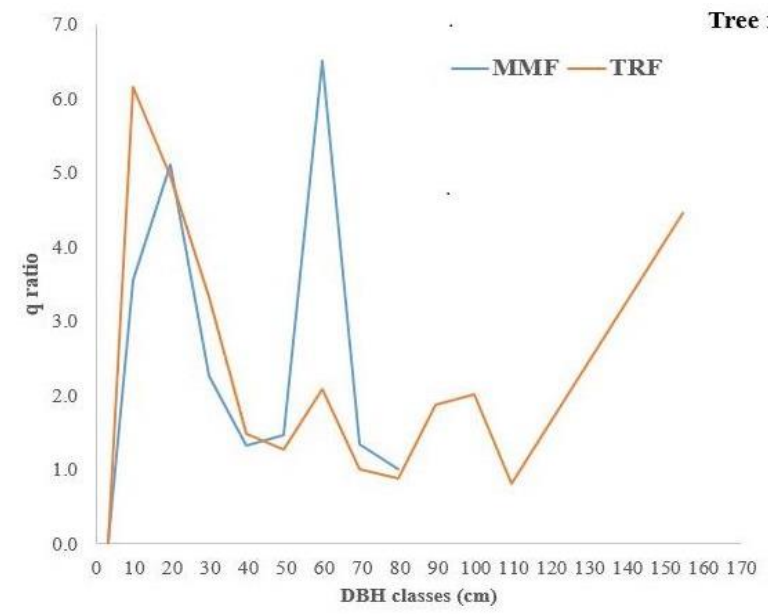

Tree recruitment patterns

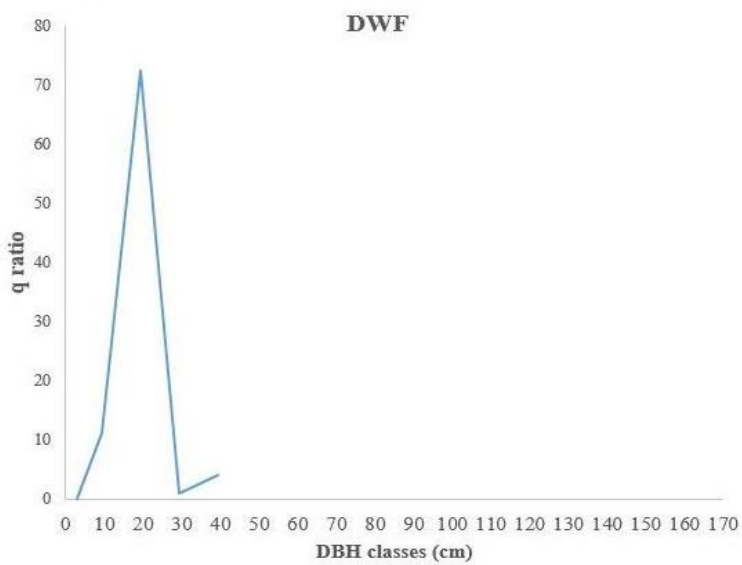

Figure 5. Trend in regeneration and recruitment process in three natural forest types in Kenya. [TRF= Tropical rain forest; $\mathrm{MMF}=$ Tropical moist montane forest; $\mathrm{DWF}=$ Tropical dry woodland forest $]$

The recruitment process of individuals into the different development stages was not regular (Fig. 5). There has been reported heavy logging activities in Kakamega (Fashing et al. 2003, Momanyi 2007, Mutiso et al. 2013) and at Mt Elgon forests over past decades (Hitimana et al. 2004, Hitimana et al. 2010) which may have distorted recruitment patterns. The number of seedlings is higher than the number of saplings. There was an observed irregular trend in the moist montane forest where the stocking of trees larger than $5 \mathrm{~cm}$ DBH was lower than saplings $(1-5 \mathrm{~cm})$; with large trees: saplings ratio of 100:80. Ordinarily; there should be more saplings than large trees in forests that experience regular recruitment patterns such as in TRF (100:130) and in DWF (100:330). Seedling establishment and sapling development may have been tempered with by logging and charcoal production (Hitimana et al. 2010). However, the monitoring of regeneration establishment and resilience are required for MMF and DWF. Seed germination and seedling establishment are known to be vulnerable stages; very much sensitive to variations in microsite conditions such as edaphic, droughts, fires, tramping and grazing (Hitimana et al. 2004, Pretzsch 2009, Eshete et al. 2011, Kiruki et al. 2017). Grazing may prevent young seedlings from reaching mature stages through trampling, uprooting and accelerated site degradation (Zida et al. 2007, Eshete et al. 2009). Uniquely low recruitment trends in dry woodland forests could be as a result of environmental hardships working against seed germination and or seedling establishment. A similar trend of low seedling and sapling counts in the wider Baringo woodland was observed for Acacia tortilis as a result of high mortality rate occasioned by competition for moisture, drought, shading effects of mature trees and intense browsing (Kiyiapi 1994). Overall; the TRF was found to be more complex and diverse than the moist montane and dry woodland forest types; with DWF being the simplest and perhaps most vulnerable ecosystem among them. Rehabilitation work is required to improve stocking levels in MMF and DWF.

\section{CONCLUSIONS}

This study on regeneration and recruitment assessment in tropical forests of Kenya revealed that closedcanopy forests (TRF and MMF) had higher stocking levels and higher stocking variability for seedlings per hectare than dry woodland forest (DWF). Complete inventory effort per hectare varied with plot sizes in a reverse order across all studied forest types. The inventory cost was highest in TRF (most complex in structure and diversity) and lowest in DWF (least complex). Efficiency of complete inventory in tropical natural forests to estimate the number of seedlings per hectare depends on the size of the plot used as the data compilation unit. The required optimum data compilation units for tree seedlings were found to be below $100 \mathrm{~m}^{2}$ for all forest types. Data obtained from the $5 \mathrm{~m}$ x $5 \mathrm{~m}$ compilation units enabled to gather quality data on all diameter size classes and allowed analysis of diameter size distributions across the studied natural forest types in order to model recruitment of the tree component and trace regeneration dynamics over time. Recruitment was found to be irregular over time in all the selected forests, perhaps due to socio-ecological factors associated with each forest type. 


\section{ACKNOWLEDGEMENTS}

Authors acknowledge funding from African Forest Research Network (AFORNET) for field work. We thank local leaders in Kakamega; Mt Elgon and Loruk in Baringo; as well as field teams led by Festus Mutiso. Finally; we appreciate contributions by the GIS experts (Michael Maina and Sheila Aswani) and the Data Analyst using R-Software (Jean Victor Kwizera).

\section{REFERENCES}

Alder D \& Synnott TJ (1992) Permanent sample plot techniques for mixed tropical forest. Tropical Forestry Papers, Commonwealth Forestry Institute. University of Oxford, No.25.

Arellano G, Cala V, Fuentes A, Cayola L, Jørgensen PM \& Macía MJ (2016) A standard protocol for woody plant inventories and soil characterisation using temporary 0.1-ha plots in tropical forests. Journal of Tropical Forest Science 28: 508-516.

Avery TE \& Burkhart HE (2015) Forest Measurements, $5^{\text {th }}$ edition. Waveland Press. Illinois.

Bellefontaine R, Petit S, Pain-Orcet M, Deleporte P \& Bertault J (2002) Trees outside forests: towards better awareness. FAO Conservation guide 35. Rome.

Brown ED \& Williams BK (2016) Ecological integrity assessment as a metric of biodiversity: are we measuring what we say we are? Biodiversity Conservation 25: 1011-1035.

Burkhart HE \& Tome M (2012) Modeling forest trees and stands. Springer Science. London.

Cavalcanti FJB, Machado AS, Osokawa RT \& Cunha US (2011) Comparison of the estimated values by sampling in the characterization of the structure of a forest area in the Amazon with the information recorded in forest census. Revista Árvore 35: 1061-1068.

Churski M (2006) Age structure and diameter distribution in a southern Swedish beech dominated landscape. SLU, Southern Swedish Forest Research Centre. Alnarp. Sweden.

Cielo-Filho R, Gneri MA \& Martins FR (2009) Sampling effort and factors influencing the precision of estimates of tree species abundance in a tropical forest stand. Phytocoenologia 39(4): 377-388.

Devis LS \& Johnson KN (1987) Forest Management, $3^{\text {rd }}$ edition. Mc Graw-Hill. New York.

Eshete AW, Sterck FJ, Teketay D \& Bongers F (2009) Effects of livestock exclusion on tree regeneration in church forests of Ethiopia. Forest Ecology and Management 257(3): 765-772.

Evans J \& Turnbull JW (2004) Plantation forestry in the tropics, $3^{\text {rd }}$ edition. Oxford University Press. Oxford.

Evans TD \& Viengkham OV (2001) Inventory time-cost and statistical power: a case study of a Lao rattan. Forest Ecology and Management 150(3): 313-322.

Fashing P, Forrestel A, Scully C \& Cords M (2003) Long-term tree population dynamics and their implications for the conservation of the Kakamega forest, Kenya. Biodiversity and Conservation 13: 753-771.

Feld CK, da Silva PM, Sousa JP, de Bello F, Bugter R, Grandin U, Hering D, Lavorel S, Mountford O, Pardo I, Partel M, Rombke J, Sandin L, Jones KB \& Harrison P (2009) Indicators of biodiversity and ecosystem services: a synthesis across ecosystems and spatial scales. Oikos 118(12): 1862-1871.

Gillison AN \& Brewer KRW (1985) The use of gradient directed transects or gradsects in natural resource surveys. Journal of Environmental Management 20: 103-127.

Girma A (2012) Plant communities, species diversity, seedling bank and resprouting in Nandi forests, Kenya, (Ph. D. Thesis). University of Koblenz-Landau, Campus Koblenz.

Grainger A (1993) Controlling Tropical Deforestation. Earthscan Publications. London.

Greenwood JJD (1996) Basic techniques. In: Sutherland WJ (ed) Ecological census techniques. Cambridge University Press. Cambridge, pp. 11-110.

Groombridge B \& Jenkins M (2000) Global biodiversity, Earth's living resources in the 21st century. World Conservation Press. Cambridge.

Hanief M, Bidalia A, Meena A \& Rao KS (2016) Natural regeneration dynamics of dominant tree species along an altitudinal gradient in three different forest covers of Darhal watershed in north westernHimalaya (Kashmir), India. Tropical Plant Research 3(2): 253-262.

Harper JL (1977) Population Biology of Plants. Academic Press. London.

Hemp A (2006) Vegetation of Kilimanjaro: hidden endemics and missing bamboo. African Journal of Ecology 44: 305-328.

Herold M \& Skutsch M (2011) Monitoring, reporting and verification for national REDD+ programmes: two proposals. Environmental Research Letters 6(2011): 014002.

Hicks C, Woroniecki S, Fancourt M, Bieri M, Robles HG, Trumper K \& Mant R (2014) The relationship between biodiversity, carbon storage and the provision of other ecosystem services: Critical Review for the

www.tropicalplantresearch.com 
Forestry Component of the International Climate Fund. United Nations Environment Programme. Cambridge. UK.

Hitimana J (2000) Structure, Composition and Regeneration of Mt Elgon Moist Lower Montane Forest (Kenya) with Particular Interest in Olea capensis subsp. welwitschii. (M. Phil. Thesis). Moi University. Kenya.

Hitimana J, Kiyiapi J \& Njunge J (2004) Forest structure characteristics in disturbed and undisturbed sites of Mt Elgon moist lower montane forest, western Kenya. Forest Ecology and Management 194: 269-291.

Hitimana J, Kiyiapi J, Njunge J \& Bargerei R (2010) Disturbance indicators and population decline of logged species in Mt Elgon Forest, Kenya. African Journal of Ecology 48: 699-708.

Hitimana J, Ole Kiyiapi J \& Bekuta B (2019) Evaluating efficiency of sampling schemes in tropical natural forests: review and simulation experience from Kenya. Asian Journal of Research in Agriculture and Forestry 4(1): 1-15.

Husch B, Beers TW \& Kershaw JA (2003) Forest mensuration, $4^{\text {th }}$ edition. John Wiley \& Sons. New York.

Jaetzold R \& Schmidt H. (1983) Farm Management Handbook of Kenya, West Kenya. II/A. Ministry of Agriculture. Nairobi. Kenya, pp. 309-324.

Jayaraman K (1999) A statistical manual for forestry research. Food and Agriculture Organization. Bangkok.

Kiruki HM, van der Zanden EH, Gikuma-Njuru P \& Verburg PH (2017) The effect of charcoal production and other land uses on diversity, structure and regeneration of woodlands in a semi-arid area in Kenya. Forest Ecology and Management 391: 282-295.

Kiyiapi JL (1994) Structure and characteristics of Acacia tortilis woodland on the Njemps Flats. Advances in Geoecology 27: 47-70.

Klauberg C, Vidal E, Silva CA, de M. Bentes M \& Hudak AT (2016) Sampling methods for titica vine (Heteropsis spp.) inventory in a tropical forest. Annals of Forest Science 73: 757-764.

Kokwaro J. (1988) Conservation status of the Kakamega forest in Kenya: the easternmost relic of the equatorial rain forest of Africa. Monographs in Systematic Botany Missouri Botanocal Garden 25: 471-489.

Lackmann S (2011) Good practice in designing a forest inventory. Lesson 8. Regional Workshop: Capacity Development for Sustainable National Greenhouse Gas Inventories. AFOLU sector (CD-REDD II) Programme, 10-13 May 2011. Quito. Ecuador.

Lanly JP (1997) World forest resources: situation and prospects. Unasylva 48(3-4): 9-18.

Marimon BS, Felfili JM, Fagg CW, Marimon-Junior BH, Umetsu R, dos santos CO, Morandi P, Lima HS \& Nascimento ART (2012) Monodominance in a forest of Brosimum rubescens Taub. (Moraceae): Structure and dynamics of natural regeneration. Acta Oecologica 43: 134-139.

McWilliams WH, Westfall JA, Brose PH, Dey DC, Hatfield M, Johnson K, Laustsen KM, Lehman SL, Morin RS, Nelson MD, Ristau TE, Royo AA, Stout SL, Willard T \& Woodall CW (2015) A Regeneration Indicator for Forest Inventory and analysis: History, Sampling, Estimation, Analytics, and Potential Use in the Midwestand Northeast United States. Gen. Tech. Rep. NRS-148. United States Department of agriculture Forest Service. Newtown Square, PA.

Momanyi G (2007) The role of rural poverty in deforestation of Kakamega forest, Kenya. Journal of Discovery and Innovations 19: 302-311.

Morais R \& Sheuber M (1997) Statistical precision in phytosociological surveys. In: Proceedings of the International Symposium on Assessment and Monitoring of Forests in Tropical Dry Regions with special reference to Gallery Forests, Nov. 1996. Brasilia, pp. 135-147.

Mulatu KA, Mora B, Kooistra L \& Herold M (2017) Biodiversity monitoring in changing tropical forests, a review of approaches and new opportunities. Remote Sensing 9: 1059.

Mutiso FM, Hitimana J, Kiyiapi JL, Sang FK \& Eboh E (2013) Recovery of Kakamega tropical rainforest from anthropogenic disturbances. Journal of Tropical Forest Science 25(4): 566-576.

Myers WL \& Patil GP (1995) Simplicity, efficiency and economy in forest surveys. In: Kohl M, Bachmann P, Brassel P \& Preto G (eds) The monte Verita Conference on forest survey designs: "Simplicity versus efficiency" and assessment of non-timber resources. Swiss Federal Institute for Forest, Snow and Landscape Research, Monte Verita, Switzerland, 2-7 May 1994. Zurich, pp. 47-55.

Nassiuma DK (2000) Survey sampling: theory and methods. Nairobi University Press. Nairobi.

Nduati P, Muchiri MN, Kirongo BB, Ojuang F, Ngugi J, Atie W, Hyvönen P, Haakana H, Alm J, Balázs A \& Parikka H (2016) Improving Capacity in Forest Resources Assessment in Kenya (IC-FRA). Technical Report on the Pilot inventory. KEFRI, Muguga.

Njunge JT \& Mugo JM (2011) Composition and succession of the woody flora of South Nandi Forest, Kenya. 
Research Journal of Botany 6: 112-121.

Oldfield S \& Newton AC (2012) Integrated conservation of tree species by botanic gardens: A reference Manual. Botanic Gardens Conservation International. United Kingdom.

Omondi SF (2016) Reproductive biology and population ecology of Senegalia senegal (L.) britton within Lake Baringo woodland ecosystem, Kenya, (Ph. D. Thesis). University of Nairobi. Nairobi.

Philip MS (1994) Measuring Trees and Forests, $2^{\text {nd }}$ edition. CAB International. UK.

Phillips OL, Martinez RV, Vargas PN, Lorenzo A, Monteagudo AL, Zans MC, Sanchez WG, Cruz AP, Timana M, Yli-Halla M \& Rose S (2003) Efficient plot-based floristic assessment of tropical forests. Journal of Tropical Ecology 19: 629-645.

Picard N, Magnussen S, Banak LN, Namkosserena S \& Yalibanda Y (2010) Permanent sample plots for natural tropical forests: a rationale with special emphasis on Central Africa. Environmental Monitoring and Assessment 164: 279-295.

Poore D \& Sayer J (1991) The Management of Tropical Moist Forest Lands: Ecological Guidelines, $2^{\text {nd }}$ edition. IUCN. Gland. Switzerland.

Poorter L, Bongers F, van Rompaey RSAR \& de Klerk M (1996) Regeneration of Canopy tree species at five sites in West African moist forest. Forest Ecology and Management 84: 61-69.

Pretzsch H (2009) Forest dynamics, growth and yield, from measurement to model. Springer-Verlag.: Berlin.

Principe A, Nunes A, Pinho P, Rosario L, Correia O \& Branquinho C (2014) Modeling the long-term natural regeneration potential of woodlands in semi-arid regions to guide restoration efforts. European Journal of Forest Research 133: 757-767.

Raj A (2018) Population structure and regeneration potential of Sal dominated tropical dry deciduous forest in Chhattisgarh, India. Tropical Plant Research 5(3): 267-274.

Sarkar M \& Devi A (2014) Assessment of diversity, population structure and regeneration status of tree species in Hollongapar Gibbon Wildlife Sanctuary, Assam, Northeast India. Tropical Plant Research 1(2): 26-36.

Schreuder HT, Gregoire TG \& Wood GB (1993) Sampling methods for multiresource forest inventory. John Wiley \& Sons. New York.

Schwartz MW \& Caro TM (2003) Effect of selective logging on tree and understorey regeneration in miombo woodland in western Tanzania. African Journal of Ecology 41: 75-82.

Serna CB (1986) Degradation of Forest Resources. GCP/RAS/106/JPN, Field Doc. 15. FAO, Bangkok.

Shijo J, Herold M, Sunderlin WD \& Verchot LV (2013) REDD+ readiness: earlyinsights on monitoring, reporting and verification systems of project developers. Environmental Research Letters 8(2013): 034038.

Shiver BD \& Borders BE (1996) Sampling techniques for forest resource inventory. Wiley.

Singh KD (1993) The 1990 tropical forest resources assessment. Unasylva 44(174): 10-19

Stride G, Thomas CD, Benedick S, Hodgson JA, Jelling A, Senior MJM \& Hill JK (2018) Contrasting patterns of local richness of seedlings, saplings, and trees may have implications for regeneration in rainforest remnants. Biotropica 50(6): 889-897.

Talbot J, Lewis SL, Lopez-Gonzalez G, Brienen RJW, Monteagudo A, Baker TR, Feldpausch TR, Malhi Y, Vanderwel M, Murakami AA, Arroyo LP, Chao K, van der Heijden TEG, Keeling H, Killeen T, Neill D, Vargas PN, Gutierrez GAP, Pitman N, Quesada CA, Silveira M, Stropp J \& Phillips OL (2014) Methods to estimate aboveground wood productivity from long-term forest inventory plots. Forest Ecology and Management 320: 30-38.

Pandey VC, Bajpai O \& Singh N (2016) Plant regeneration potential in fly ash ecosystem. Urban Forestry \& Urban Greening 15: 40-44.

Wang X, Hao Z, Zhang J, Lian J, Li B, Ye J \& Yao X (2009) Tree size distributions in an old-growth temperate forest. Oikos 118: 25-36.

Weiskittel AR, Hann DW, Kershaw Jr JA \& Vanclay J (2011) Forest growth and yield modeling. WileyBlackwell. Oxford.

Wong JLG, Thornber K \& Baker N (2001) Resource assessment of non-wood forest products: experience and biometric principles. FAO, Rome.

Zida D, Sawadogo L, Tigabu M, Tiveau D \& Odena PC (2007) Dynamics of sapling population in savanna woodlands of Burkina Faso subjected to grazing, early fire and selective tree cutting for a decade. Forest Ecology and Management 243: 102-115. 
Appendix I: R codes for creating various plot sizes.

\section{Introduction}

This process is the same in $\mathrm{R}$ studio for all the three forests. We use Mt. Elgon site to illustrate it. We just update the name of the forest in the function and run to get output.

\section{Merging $5 \mathrm{~m} \times 5 \mathrm{~m}$ plots to create $10 \mathrm{~m} \times 5 \mathrm{~m}$ plots}

Field data collection from the forest was done and organized in 400 plots of equal size of $5 \mathrm{~m} \times 5 \mathrm{~m}$ (Smallest plot size tested in the study).

\section{Display of grid for four hundred $5 \mathrm{~m} \times 5 \mathrm{~m}$ plots is available (Appendix II. A.)}

Reorganising field data from same forest in $10 \mathrm{~m} \times 5 \mathrm{~m}$ plot size was done in $\mathrm{R}$ as described below. It required having 1 ha forest divided it into 200 plots of $10 \mathrm{~m} \times 5 \mathrm{~m}$ each. Each plot here is going to be twice as large as the the plots in the previous part.

We create the 200 plots here by merging every two consecutive plots (vertically) from the initial grid of 400 plots.

First, let us identify the unique plots in order

plots =unique(mt_elgon\$plot.no.)

plots $=$ as.character(plots)

We take the odd plot number eg 1111 to represent the new plot that is created by merging the two plots 1111 and 1112. The unique plots are arranged in ascending order from 1 through 400 . The position of the plot in this arrangement (between 1 and 400) can be separated as either even eg 2 or odd eg 1 . The first and second lines of the code below checks if the position is even or odd and creates a list with the values TRUE if the position is even and FALSE if the position is odd.

is.even $=$ function $(\mathrm{x}) \mathrm{x} \% \% 2==0$

even $=$ is.even $(1:$ length(plots)

Finally, the two lists plots and even are merged together to create a table with two rows, one for plot number and another indicating whether the position is odd or even, and 400 rows, one for each unique plot number.

mytable $=$ cbind $($ plots, even $)$

mytable $=$ as.data.frame $($ mytable $)$

Our new table is named mytable

Unique number for the new created plot of $10 \mathrm{~m} \times 5 \mathrm{~m}$ is the odd plot number from each pair of small plots that were merged. In $\mathrm{R}$, we create another column in mytable. This column will contain the uniqueplot number.The first line of code below creates another column and calls it newplots. The second part of the code adds the values of plot number that we want.

mytable $=$ mutate $($ mytable, newplots $=$ plots $)$

mytable[mytable $\$$ even $==T,][3]=$ mytable $[$ mytable $\$$ even $==F],[3]$

We use this table to check for all values of plot number in our mt_elgon data set that match the values of plots in mytable and we replace them with the values of newplots in mytable. We also ensure the values in these three columns are of the same "data type".

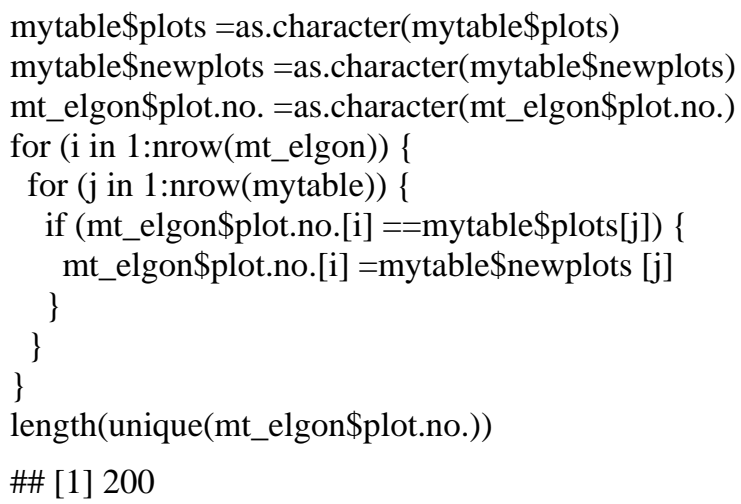

We now have 200 unique plots from initial 400. We can now go ahead with our analysis just in the same way as it is done in the 400 plots.

uniq_plots =as.character(unique(mt_elgon\$PLOT.NO.))

length(uniq_plots)

\#\# [1] 200 
Arranging the plots appropriately;

uniq_plots =cbind(uniq_plots[1:20], uniq_plots[21:40], uniq_plots[41:60], uniq_plots[61:80], uniq_plots[81:100], uniq_plots[101:120], uniq_plots[121:140], uniq_plots[141:160], uniq_plots[161:180], uniq_plots[181:200]) uniq_plots =as.data.frame(uniq_plots)

Display of grid for two hundred $10 \mathrm{~m} \times 5 \mathrm{~m}$ plots is available (Appendix II.B)

\section{Merging $10 \mathrm{~m} \times 5 \mathrm{~m}$ plots to create $10 \mathrm{~m} \times 10 \mathrm{~m}$ plots}

The 200 plots grid is made of 20 columns and 10 rows. We need to merge two consecutive plots (horizontally) to create 10 columns, and obtain a grid of 10 columns by 10 rows as follows.

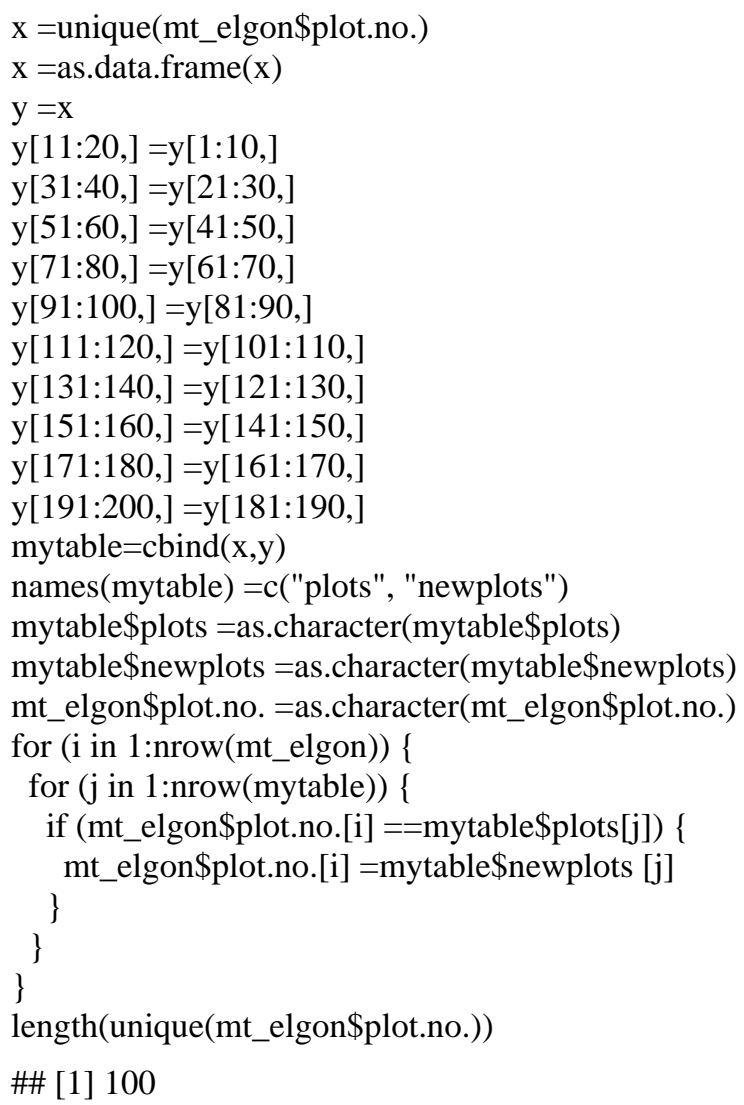

We now have 100 unique plots from initial 200 plots. We can now go ahead with our analysis just like in the 400 plots.

uniq_plots =as.character(unique(mt_elgon\$PLOT.NO.))

length(uniq_plots)

\#\# [1] 100

Then we arrange the plots appropriately.

uniq_plots =cbind(uniq_plots[1:10], uniq_plots[11:20], uniq_plots[21:30], uniq_plots[31:40], uniq_plots[41:50], uniq_plots[51:60], uniq_plots[61:70], uniq_plots[71:80], uniq_plots[81:90], uniq_plots[91:100])

uniq_plots =as.data.frame(uniq_plots)

Display of grid for one hundred $10 \mathrm{~m} \times 10 \mathrm{~m}$ plots is available (Appendix II.C)

\section{Merging $10 \mathrm{~m} \times 10 \mathrm{~m}$ plots to create $20 \mathrm{~m} \times 20 \mathrm{~m}$ plots}

\subsection{Merging pairs of consecutive plots vertically to create $20 \mathrm{~m} \times 10 \mathrm{~m}$ plots}

First, let us identify the unique plots from the list of $10 \mathrm{~m} \times 10 \mathrm{~m}-$ plots

plots =unique(mt_elgon\$plot.no.)

plots $=$ as.character(plots)

The unique plots are arranged in order from 1 through 100. The position of the plot in this arrangement (between 1 and 100) can be separated as either even eg 2 or odd eg 1 . The first and second lines of the code 
below check if the position is even or odd and create a list with the values TRUE if the position is even and FALSE if the position is odd.

Finally, the two lists plots and even are merged together to create a table with two rows: one for plot number and another indicating whether the position is odd or even and 100 rows, one for each unique plot number.

is.even $=$ function $(\mathrm{x}) \mathrm{x} \% \% 2==0$

even $=$ is.even $(1:$ length(plots))

mytable $=$ cbind(plots,even)

mytable $=$ as.data.frame $($ mytable $)$

Our new table is named mytable

Unique number for the new created plot of $20 \mathrm{~m} \times 10 \mathrm{~m}$ is the odd plot number from each pair of $10 \mathrm{mx} 10 \mathrm{~m}$ plots that were merged. In R, we create another column in mytable. This column will contain the uniqueplot number for $20 \mathrm{~m} \times 10 \mathrm{~m}$ plot.The first line of code below creates another column and calls it newplots. The second part of the code adds the values of plot number that we want.

mytable $=$ mutate $($ mytable, newplots $=$ plots $)$

mytable[mytable $\$$ even $==\mathrm{T},][3]=$ mytable $[$ mytable $\$$ even $==F],[3]$

mytable $\$$ plots =as.character(mytable $\$$ plots)

mytable\$newplots $=$ as.character(mytable $\$$ newplots)

mt_elgon\$plot.no. =as.character(mt_elgon\$plot.no.)

for (i in 1:nrow(mt_elgon)) \{

for ( $\mathrm{j}$ in 1:nrow(mytable)) \{

if (mt_elgon\$plot.no.[i] ==mytable\$plots[j]) \{

mt_elgon\$plot.no.[i] =mytable\$newplots [j]

length(unique(mt_elgon\$plot.no.))

\#\# [1] 50

We now have 50 unique plots from initial 100 plots

\subsection{Merging consecutive $20 \mathrm{~m} \times 10 \mathrm{~m}$ plots horizontally to form $20 \mathrm{~m} \times 20 \mathrm{~m}$ plots}

The fifty $20 \mathrm{~m} \mathrm{x} 10 \mathrm{~m}$ plots are arranged in 5 rows and 10 columns. In $\mathrm{R}$, we need to reduce the 10 columns with $10 \mathrm{~m}$ length each to 5 columns with $20 \mathrm{~m}$ length each.

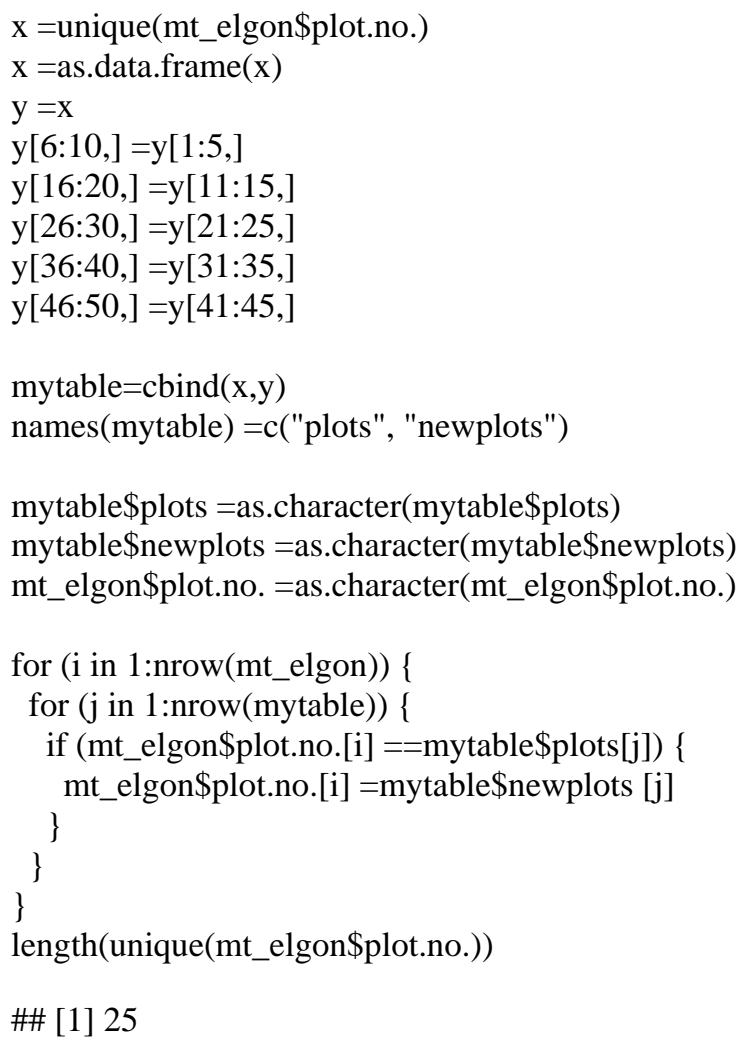


We now have 25 unique plots from initial 50 and can go ahead with our data analysis from them.

uniq_plots =as.character(unique(mt_elgon\$PLOT.NO.))

length(uniq_plots)

\#\# [1] 25

Appropriate arrangement of the plots through are codes:

uniq_plots =cbind(uniq_plots[1:5], uniq_plots[6:10], uniq_plots[11:15], uniq_plots[16:20], uniq_plots[21:25]) uniq_plots =as.data.frame(uniq_plots)

Display of grid for twenty-five $20 \mathrm{~m} \times 20 \mathrm{~m}$ plots is available (Appendix II.D)

Appendix II: Sampling frames for different plot sizes.

II.A: Grid of the $4005 \mathrm{~m} \times 5 \mathrm{~m}$-plots: case in Mt Elgon $100 \mathrm{~m} \times 100 \mathrm{~m}$ - Forest Unit.

\begin{tabular}{|c|c|c|c|c|c|c|c|c|c|c|c|c|c|c|c|c|c|c|c|}
\hline 1111 & 11121 & 11141 & \begin{tabular}{|l|l|}
11161 \\
\end{tabular} & 11181 & 111101 & 111121 & 111141 & 111161 & 111181 & 111201 & 111221 & 111241 & 111261 & 111281 & 111301 & 111321 & 111341 & 111361 & 111381 \\
\hline 1112 & 11122 & 11142 & 11162 & \begin{tabular}{|l|l|}
11182 \\
\end{tabular} & 111102 & 111122 & 111142 & 111162 & 111182 & 111202 & 111222 & 111242 & 111262 & 111282 & 2111302 & 111322 & 111342 & 111362 & 111382 \\
\hline 1113 & 11123 & 11143 & |11163 & \begin{tabular}{|l|l|}
11183 \\
\end{tabular} & 111103 & 111123 & 111143 & 111163 & 111183 & 111203 & 111223 & 111243 & 111263 & 111283 & $3 \mid 111303$ & 111323 & 111343 & 111363 & 111383 \\
\hline 1114 & 11124 & 11144 & 11164 & 11184 & 111104 & 111124 & 111144 & 111164 & 111184 & 111204 & 111224 & 111244 & 111264 & 111284 & 4. 111304 & 111324 & 111344 & 111364 & 111384 \\
\hline 1115 & 11125 & 11145 & 11165 & 11185 & 111105 & 111125 & 111145 & 111165 & 111185 & 111205 & 111225 & 111245 & 111265 & 111285 & 111305 & 111325 & 111345 & 111365 & 111385 \\
\hline 1116 & 11126 & 11146 & 11166 & 11186 & 111106 & 111126 & 111146 & 111166 & 111186 & 111206 & 111226 & 111246 & 111266 & 111286 & 111306 & 111326 & 111346 & 111366 & 111386 \\
\hline 1117 & 11127 & 11147 & 11167 & 11187 & 111107 & 111127 & 111147 & 111167 & 111187 & 111207 & 111227 & $\mid 111247$ & 111267 & $\mid 111287$ & 711307 & 111327 & 111347 & 111367 & 111387 \\
\hline 1118 & 11128 & 11148 & 11168 & 11188 & 111108 & 111128 & 111148 & 111168 & 111188 & 111208 & 111228 & 111248 & 111268 & 111288 & 111308 & 111328 & 111348 & 111368 & 111388 \\
\hline 1119 & 11129 & 11149 & 11169 & 11189 & 111109 & 111129 & 111149 & 111169 & 111189 & 111209 & 111229 & 111249 & 111269 & 111289 & 111309 & 111329 & 111349 & 111369 & 111389 \\
\hline 11110 & 11130 & 11150 & 11170 & 11190 & 111110 & 111130 & 111150 & 111170 & 111190 & 111210 & 111230 & 111250 & 111270 & 111290 & 111310 & 111330 & 111350 & 111370 & 111390 \\
\hline 11111 & 11131 & 11151 & 11171 & 11191 & 111111 & 111131 & 111151 & 111171 & 111191 & 111211 & 111231 & 111251 & 111271 & 111291 & 111311 & 111331 & 111351 & 111371 & 111391 \\
\hline 11112 & 11132 & 11152 & 11172 & 11192 & 111112 & 111132 & 111152 & 111172 & 111192 & 111212 & 111232 & 111252 & 111272 & 111292 & 111312 & 111332 & 111352 & 111372 & 111392 \\
\hline 11113 & 11133 & 11153 & 11173 & 11193 & 111113 & 111133 & 111153 & 111173 & 111193 & 111213 & 111233 & 111253 & 111273 & 111293 & 111313 & 111333 & 111353 & 111373 & 111393 \\
\hline 11114 & 11134 & 11154 & 11174 & $\mid 11194$ & 111114 & 111134 & 111154 & 111174 & 111194 & 111214 & 111234 & 111254 & 111274 & 111294 & 111314 & 111334 & 111354 & 111374 & 111394 \\
\hline 11115 & 11135 & 11155 & 11175 & 11195 & 111115 & 111135 & 111155 & 111175 & 111195 & 111215 & 111235 & 111255 & 111275 & 111295 & 111315 & 111335 & 111355 & 111375 & 111395 \\
\hline 11116 & 11136 & 11156 & 11176 & 11196 & 1116 & 111136 & 111156 & 111176 & 111196 & 111216 & 111236 & 111256 & 111276 & 111296 & 5111316 & 111336 & 111356 & 111376 & 111396 \\
\hline 11117 & 11137 & 11157 & 11177 & 11197 & 111117 & 111137 & 111157 & 111177 & 111197 & 111217 & 111237 & 111257 & 111277 & 111297 & $\mid 111317$ & $\mid 111337$ & 111357 & 111377 & 111397 \\
\hline 11118 & 11138 & 11158 & 11178 & \begin{tabular}{|l|}
11198 \\
\end{tabular} & 1118 & 111138 & 1158 & 11117 & 111198 & 111218 & 111238 & 111258 & 111278 & 111298 & 111318 & 111338 & 111358 & 111378 & 111398 \\
\hline 11119 & 11139 & 11159 & 11179 & \begin{tabular}{|l|l|}
11199 \\
\end{tabular} & 111119 & 1139 & 1159 & 1179 & 111199 & 111219 & 111239 & 111259 & 111279 & 111299 & 111319 & 111339 & 111359 & 111379 & 111399 \\
\hline 11120 & 11140 & 11160 & 11180 & 111100 & 111120 & 111140 & 111160 & 111180 & 111200 & 111220 & 111240 & 111260 & 111280 & 111300 & 111320 & 111340 & 111360 & 111380 & 111400 \\
\hline
\end{tabular}


Hitimana et al. 2019

II.B: Grid of the $20010 \mathrm{~m} \times 5 \mathrm{~m}$-plots: case in Mt Elgon $100 \mathrm{~m} \times 100 \mathrm{~m}$ - Forest Unit.

\begin{tabular}{|c|c|c|c|c|c|c|c|c|c|c|c|c|c|c|c|c|c|c|c|}
\hline 1111 & 11122 & 11141 & 11161 & 11181 & 111100 & 111120 & 111140 & 111160 & 111180 & 111201 & 111221 & 111241 & 111261 & 111281 & 111300 & 111320 & 111340 & 111360 & \\
\hline 1113 & 11124 & 11143 & 11163 & 11183 & 111102 & 111122 & 111142 & 111162 & 111182 & 111203 & 111223 & 111243 & 111263 & 111283 & 111302 & 111322 & 111342 & 111362 & \\
\hline 1116 & 11126 & 11145 & 11165 & 11185 & 111104 & 111124 & 111144 & 111164 & 111184 & 111205 & 111225 & 111245 & 111265 & 111285 & 111304 & 111324 & 111344 & 111364 & 1113 \\
\hline 1118 & 11128 & 11147 & 11167 & 11187 & 111106 & 111126 & 111146 & 111166 & 111186 & 111207 & 111227 & 111247 & 111267 & 111287 & 111306 & 111326 & 111346 & 111366 & 111386 \\
\hline 11111 & 11131 & 11149 & 11169 & 11189 & 111108 & 111128 & 111148 & 111168 & $111188 \mid$ & 111209 & 111229 & 111249 & 111269 & 111289 & 111308 & 111328 & 111348 & 111368 & \\
\hline 11113 & 11133 & 11150 & 11170 & 11190 & 111111 & 111131 & 111151 & 111171 & 1111191| & 111210 & 111230 & 111250 & 111270 & 111290 & 111311 & 111331 & 111351 & 111371 & \\
\hline 11115 & 11135 & 11152 & 11172 & 11192 & 111113 & 111133 & 111153 & 111173 & 111193 & 111212 & 111232 & 111252 & 111272 & 111292 & 111313 & 111333 & 111353 & 111373 & 111393 \\
\hline 11117 & 11137 & 11154 & 11174 & 11194 & 111115 & 111135 & 111155 & 111175 & 111195 & 111214 & 111234 & 111254 & 111274 & 111294 & 111315 & 111335 & 111355 & 111375 & 111395 \\
\hline 11119 & 11139 & 11156 & 11176 & 11196 & 111117 & 111137 & 111157 & 111177 & 111197 & 111216 & 111236 & 111256 & 111276 & 111296 & 111317 & 111337 & 111357 & 111377 & 111397 \\
\hline 11120 & 11140 & 11158 & 11178 & 11198 & 111119 & 111139 & 111159 & 111179 & 111199 & 111218 & 111238 & 111258 & 111278 & 111298 & 111319 & 111339 & 111359 & 111379 & 111399 \\
\hline
\end{tabular}

II.C: Grid of the $10010 \mathrm{~m} \times 10 \mathrm{~m}$-plots: case in Mt Elgon $100 \mathrm{~m} \times 100 \mathrm{~m}-$ Forest Unit.

\begin{tabular}{|l|l|l|l|l|l|l|l|l|l|}
\hline 1111 & 11141 & 11181 & 111120 & 111160 & 111201 & 111241 & 111281 & 111320 & 111360 \\
\hline 1113 & 11143 & 11183 & 111122 & 111162 & 111203 & 111243 & 111283 & 111322 & 111362 \\
\hline 1116 & 11145 & 11185 & 11124 & 111164 & 111205 & 111245 & 111285 & 111324 & 111364 \\
\hline 1118 & 11147 & 11187 & 111126 & 111166 & 111207 & 111247 & 111287 & 111326 & 111366 \\
\hline 11111 & 11149 & 11189 & 111128 & 111168 & 111209 & 111249 & 111289 & 111328 & 111368 \\
\hline 11113 & 11150 & 11190 & 111131 & 111171 & 111210 & 111250 & 111290 & 111331 & 111371 \\
\hline 11115 & 11152 & 11192 & 111133 & 111173 & 111212 & 111252 & 111292 & 111333 & 111373 \\
\hline 11117 & 11154 & 11194 & 111135 & 111175 & 111214 & 111254 & 111294 & 111335 & 111375 \\
\hline 11119 & 11156 & 11196 & 111137 & 111177 & 111216 & 111256 & 111296 & 111337 & 111377 \\
\hline 11120 & 11158 & 11198 & 111139 & 111179 & 111218 & 111258 & 111298 & 111339 & 111379 \\
\hline
\end{tabular}

II.D: Grid of the $2520 \mathrm{~m} \times 20 \mathrm{~m}$-plots: case in Mt Elgon $100 \mathrm{~m} \times 100 \mathrm{~m}$ - Forest Unit.

\begin{tabular}{|l|l|l|l|l|}
\hline 1111 & 11181 & 111160 & 111241 & 111320 \\
\hline 1116 & 11185 & 111164 & 111245 & 111324 \\
\hline 11111 & 11189 & 111168 & 111249 & 111328 \\
\hline 11115 & 11192 & 111173 & 111252 & 111333 \\
\hline 11119 & 11196 & 111177 & 111256 & 111337 \\
\hline
\end{tabular}

